\title{
Quantifying Methane Emissions from Natural Gas Water Heaters
}

Authors: Eric D. Lebel ${ }^{1}$, Harmony S. Lu ${ }^{1}$, Simone A. Speizer ${ }^{1}$, Colin J. Finnegan ${ }^{1}$, Robert B.

Jackson $^{1,2}$

1. Department of Earth System Science, Stanford University, Stanford, CA

2. Woods Institute for the Environment and Precourt Institute for Energy, Stanford

University, Stanford, $C A$

SUPPORTING INFORMATION

10 pages

6 figures

2 tables 


\section{S1: Photos of Experimental Setup}
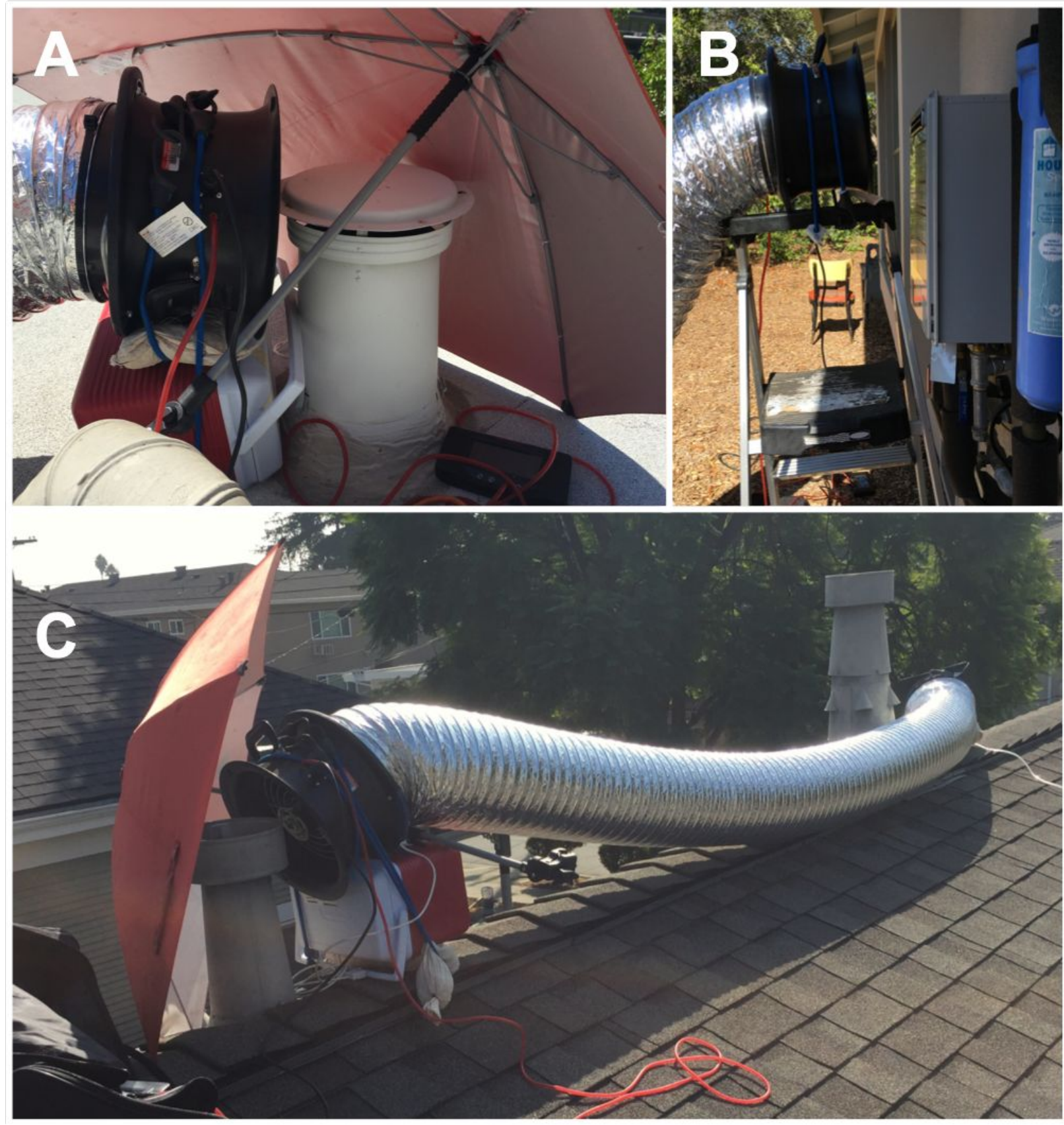

Figure S1: Visual of the Duct Blaster sampling water heaters. (A) The Duct Blaster is sampling from the exhaust vent atop a roof. (B) An external TWH is being measured by the duct blaster. (C) A zoom out of the Duct Blaster sampling on top of a roof. The emissions are measured from the hose at the end of the exhaust. 


\section{S2: Duct Blaster Testing with Controlled Methane Releases}

We tested the Duct Blaster outdoors with controlled methane releases. We used $2.5 \%$ methane at flow rates ranging from 0.5-1.0 LPM and Duct blaster flows ranging from 405-997 CFM.

Ultimately, we found there was an insignificant relationship between the percent error in our controlled releases and the Duct Blaster flow $(\mathrm{p}=0.08)$, so we took the simple average of all the errors, which we found to be $10.7 \%$. We corrected all of our measurements by reducing the measured emissions by $10.7 \%$.

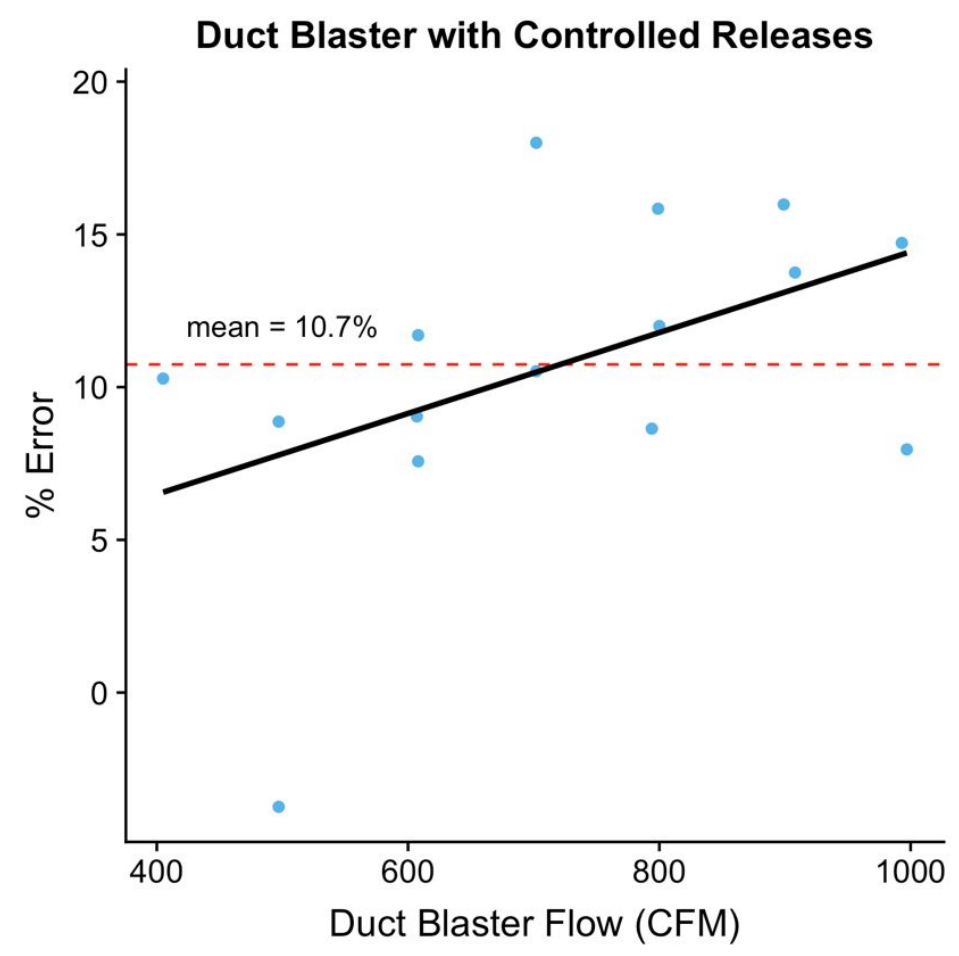

Figure S2: Relationship between Duct Blaster Flow and \% Error during a controlled release test outdoors. The black line is the trendline of the trials, $p=0.08$; adj. $r^{2}=0.16$. We took the simple average of the trials, which had a mean error of $10.7 \%$, which we used to correct all of our measurements. 


\section{S3: Duct Blaster Influencing Emission Rates}

We examined the potential of the Duct Blaster to influence emissions rates by creating a pressure differential. We tested two SWHs while off and two TWHs while on and varied the intake rate of the Duct Blaster between 152-1155 CFM over the appliances. We found that the relationship between Duct Blaster flow was not significant with measured $\mathrm{CH}_{4}$ emissions for $\mathrm{SWHs}$ $(\mathrm{p}=0.95)$, and didn't appear to have an effect on TWHs ( $\mathrm{p}=0.33$; Figure $\mathrm{S} 4)$.
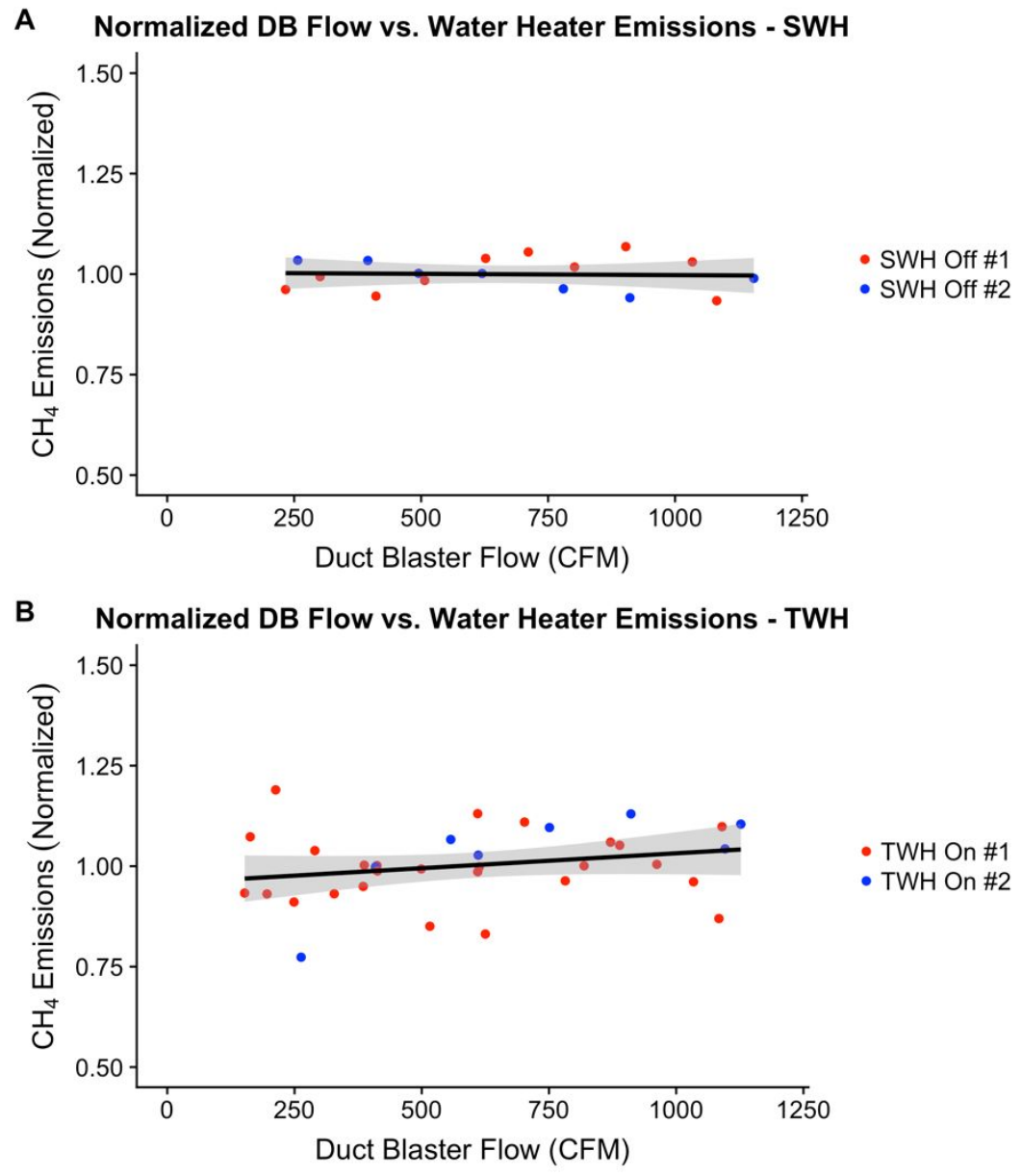

Figure S3: Two SWHs were tested while off and two TWHs were tested while on at constant hot water demand to see whether the Duct Blaster fan speed altered methane emissions; if so, a positive linear line would be expected. A positive slope could also result from an incomplete capture of emissions at low Duct Blaster speeds. The values were normalized to the value of the trendline at a Duct Blaster speed of 600 CFM. (A) There is no significant p-value of the slope for either SWH. SWH \#2, which is 
close to 0.05, has a negative slope. Combining both SWH datasets, the p-value is 0.95 , extremely insignificant. (B) TWH \#2 has a significant $(<0.05)$ and positive slope, but the sudden drop in the point at 250 CFM suggests there may have been an incomplete capture of emissions. Combining both TWH datasets, the p-value is 0.33 , which is quite insignificant.

\section{S4: Natural Gas Flow Compared with $\mathrm{CO}_{2}$ Emissions}

For each measurement, we measured the natural gas used by counting the revolutions on the gas meter. We also measured $\mathrm{CO}_{2}$ emissions on the Picarro during Steady-State On periods. A plot of natural gas flow vs. measured $\mathrm{CO}_{2}$ emissions provides evidence that we were in fact capturing all the emissions with the Duct Blaster.

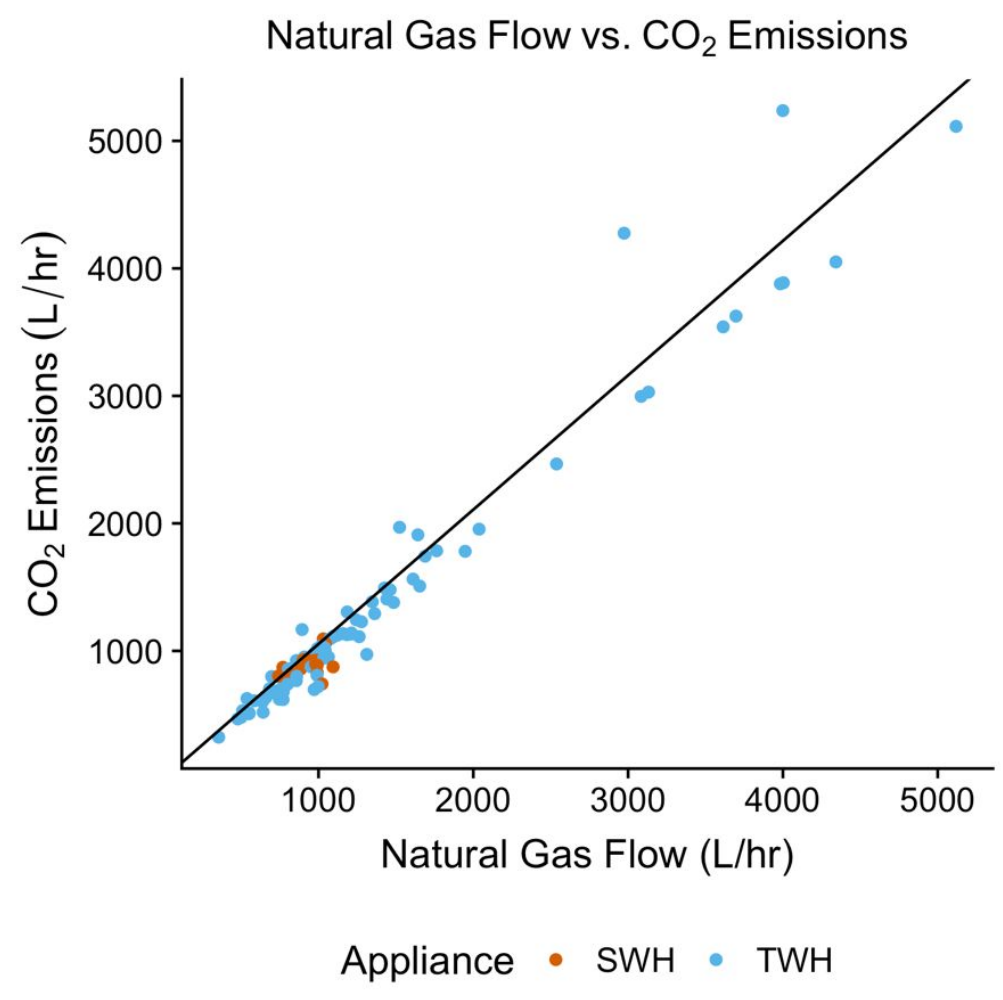

Figure S4: Relationship between natural gas flow measured on the home's natural gas meter and CO $\mathrm{Cmissions}_{2}$ measured using the Duct Blaster and Picarro analyzer. The black line is a trendline of the expected ratio of $\mathrm{CO}_{2}$ to natural gas given the local natural gas composition (slope=1.054). Overall, there was close agreement between the 
$\mathrm{CO}_{2}$ emissions calculated from the Duct Blaster the natural gas flow that was recorded on the meter - the calculated linear regression had a slope of 1.047, adj. $r^{2}=0.956, p<<0.001$

\section{S5: TWH Response to Variable Demands}

Since TWHs adjust their burner to instantaneous hot water demand, we measured each component of TWH emissions spanning the range of possible hot-water flow rates we could produce from an individual faucet. We plotted individual measurements during SS On of the percent leaked gas and the pulse of $\mathrm{CH}_{4}$ while turning on in TWHs (Figure 3A,B). When plotted using only datapoints from locations where we sampled a water flow $>3$ GPM, we found an insignificant trend in percent leakage with respect to water flow (Fig. 3A; $p=0.10$ ). However, the slope of the On Pulse was highly significant (Figure 3B; $<<0.001$ ), with a positive slope of the line. Ultimately, our water flow sampling distribution was representative of the general trends of hot water demands as flow demand is typically low (i.e. hand washing), compared to the few instances of high hot water flow demand (i.e. drawing water from a tub). Even a typical low-flow shower head has a comparable water flow to an average kitchen sink; in many homes without a tub, we were unable to achieve a hot water flow demand of $>3$ GPM using only one faucet.
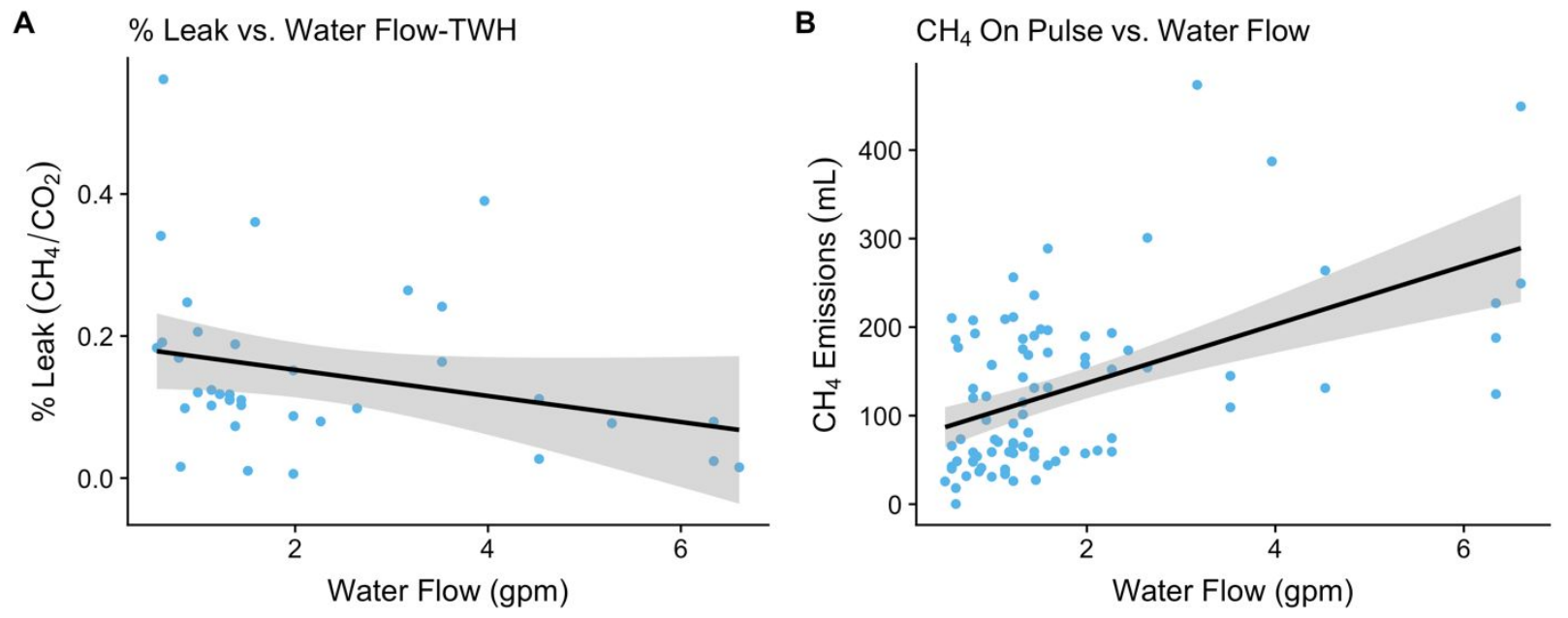
Figure S5: Percent leakage or emissions of $\mathrm{CH}_{4}$ or $\mathrm{CO}_{2}$ as a function of water flow. (A) Water flow vs. Percent Incomplete Combustion for TWHs over a span of water flow ranges on TWHs, using only WHs for which we measured a flow of 3 GPM or greater. The incomplete combustion fraction stays relatively constant ( $p=0.033$; adj. $\left.r^{2}=0.044\right)$. (B) Effect of hot water demand verses methane emissions from TWH while turning on ( $p<0.001$; adj. $\left.r^{2}=0.252\right)$.

\section{S6: Multiple on peaks for water heaters close to trigger point}

In some rare instances, water heaters would produce multiple on peaks, typically close to the threshold of activation for the water heaters. For these instances, all the peaks were integrated to produce a total value for the On Pulse, as seen in Figure S1.

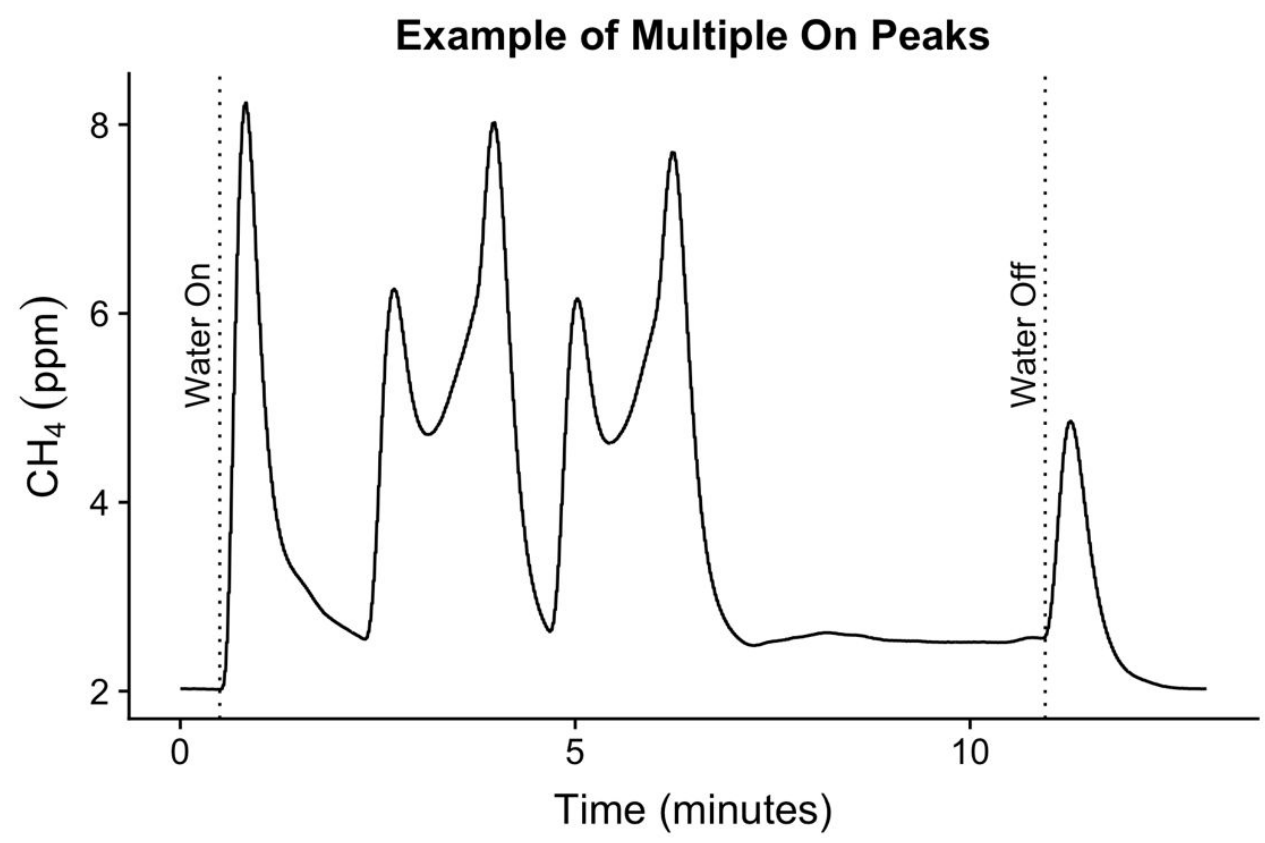

Figure S6: 3 sequential On Pulses are shown in an example with a water draw close to the threshold of activation for this particular TWH. 
S7: Comparing our Results of Methane Emissions to Merrin \& Francisco ${ }^{1}$

\begin{tabular}{|c|c|c|c|c|c|}
\hline & & \multicolumn{2}{|c|}{ Storage Water Heaters } & \multicolumn{2}{|c|}{ Tankless Water Heaters } \\
\hline & & This Study & $\begin{array}{l}\text { Merrin \& } \\
\text { Francisco }\end{array}$ & This Study & $\begin{array}{l}\text { Merrin \& } \\
\text { Francisco }\end{array}$ \\
\hline \multirow{7}{*}{ 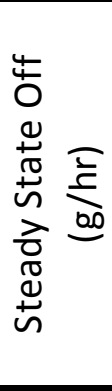 } & Median & 0.064 & NA & 0.036 & NA \\
\hline & Mean & 0.16 & NA & 0.061 & NA \\
\hline & Standard Deviation & 0.20 & NA & 0.077 & NA \\
\hline & Minimum & 0.011 & NA & 0.0012 & NA \\
\hline & Maximum & 0.70 & NA & 0.30 & NA \\
\hline & 1st Quartile & 0.027 & NA & 0.013 & NA \\
\hline & 3rd Quartile & 0.21 & NA & 0.086 & NA \\
\hline \multirow{7}{*}{ 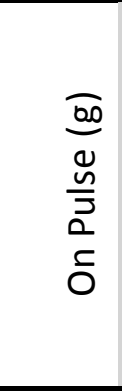 } & Median & 0.0031 & 0.00036 & 0.082 & 0.022 \\
\hline & Mean & 0.011 & 0.0019 & 0.087 & 0.092 \\
\hline & Standard Deviation & 0.016 & 0.0035 & 0.052 & 0.14 \\
\hline & Minimum & -0.010 & $9.10 \mathrm{E}-06$ & 0.0085 & 0.00088 \\
\hline & Maximum & 0.049 & 0.013 & 0.18 & 0.47 \\
\hline & 1st Quartile & 0.0011 & 0.000088 & 0.040 & 0.0058 \\
\hline & 3rd Quartile & 0.017 & 0.0016 & 0.12 & 0.12 \\
\hline \multirow{7}{*}{ 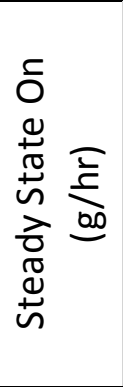 } & Median & -0.0024 & 0.012 & 1.3 & 1.1 \\
\hline & Mean & 0.041 & 0.028 & 1.5 & 4.1 \\
\hline & Standard Deviation & 0.14 & 0.057 & 1.1 & 6.8 \\
\hline & Minimum & -0.029 & 0.000025 & 0.20 & 0.00079 \\
\hline & Maximum & 0.60 & 0.37 & 4.7 & 25 \\
\hline & 1st Quartile & -0.013 & 0.00084 & 0.63 & 0.047 \\
\hline & 3rd Quartile & 0.026 & 0.032 & 1.7 & 4 \\
\hline \multirow{7}{*}{ 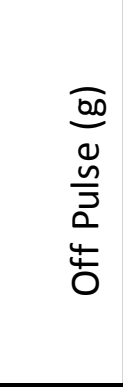 } & Median & 0.0053 & 0.002 & 0.025 & 0.039 \\
\hline & Mean & 0.0075 & 0.032 & 0.031 & 0.058 \\
\hline & Standard Deviation & 0.0086 & 0.14 & 0.019 & 0.059 \\
\hline & Minimum & -0.0029 & 0.00019 & 0.011 & 0.00053 \\
\hline & Maximum & 0.024 & 0.63 & 0.080 & 0.18 \\
\hline & 1st Quartile & 0.0016 & 0.00052 & 0.019 & 0.016 \\
\hline & 3rd Quartile & 0.011 & 0.0028 & 0.035 & 0.074 \\
\hline \multirow{7}{*}{ 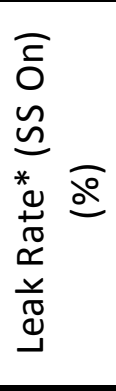 } & Median & $-0.00039 \%$ & $0.0016 \%$ & $0.15 \%$ & $0.029 \%$ \\
\hline & Mean & $0.0061 \%$ & $0.0036 \%$ & $0.20 \%$ & $0.12 \%$ \\
\hline & Standard Deviation & $0.023 \%$ & $0.0072 \%$ & $0.17 \%$ & $0.21 \%$ \\
\hline & Minimum & $-0.0071 \%$ & $0.0000040 \%$ & $0.012 \%$ & $0.000020 \%$ \\
\hline & Maximum & $0.097 \%$ & $0.046 \%$ & $0.71 \%$ & $0.84 \%$ \\
\hline & 1st Quartile & $-0.0022 \%$ & $0.00011 \%$ & $0.11 \%$ & $0.0014 \%$ \\
\hline & 3rd Quartile & $0.0041 \%$ & $0.0042 \%$ & $0.21 \%$ & $0.10 \%$ \\
\hline
\end{tabular}


*Leak Rates were determined volumetrically for our study, but were mass-based for Merrin \& Francisco

\section{S8: Multiple Linear Regression with TWHs}

The relatively low p-values $(<0.05)$ for age on the SS Off and Turn Off periods, as well as the marginally significant P-Value for age on SS On (0.078) suggest that some variance in TWH emissions may be attributable to age. There are increasing emissions with older TWHs during each of these three categories. Interestingly, the Turn On Pulse vs. Age had a high p-value, suggesting that these emissions are not associated with Age, and might be a consequence of the mechanical design of the combustion chamber. We recommend further research into determining the cause of the TWH emissions.

\begin{tabular}{|r|c|c|c|c|}
\hline & SS On & SS Off & Turn On & Turn Off \\
\hline Adj. R Squared & 0.029 & 0.096 & -0.016 & 0.085 \\
\hline Intercept P-Value & 0.012 & 0.074 & 0.0000073 & 0.00052 \\
\hline AGE P-Value & 0.078 & 0.011 & 0.41 & 0.012 \\
\hline Condensing P-Value & 0.73 & 0.23 & 0.84 & 0.47 \\
\hline
\end{tabular}

Table S8: Results from Multiple Linear Regression on each of the four components of TWH emissions-Steady-state On, Steadystate Off, Turn On, Turn Off —on age and condensing status. 


\section{Reference}

(1) Merrin, Z.; Francisco, P. W. Unburned Methane Emissions from Residential Natural Gas Appliances. Environ. Sci. Technol. 2019, 53 (9), 5473-5482.

https://doi.org/10.1021/acs.est.8b05323. 